We continue to find an effect of the Gulf conflict manifested as increased symptomatic distress. In our study, the modest increase in psychiatric disorders do no fully explain ill health in Gulf veterans.

We thank the UK Ministry of Defence for help with tracing veterans, Graham Dunn for his expert advice and comments on the statistics, and the veterans who participated.

Contributors: See bmj.com

Funding: US Department of Defence.

Competing interests: None declared.

1 The Iowa Persian Gulf Study Group. Self-reported illnesses and health status among Gulf war veterans. A population based study. JAMA 1997;277:238-45.

2 Kang H, Mahan C, Lee K, Magee C, Murphy F. Illnesses among United States veterans of the Gulf war: a population-based survey of 30,000 veterans. J Occup Envirom Med 2000;42:491-501.

3 Gray G, Smith T, Kang H, Knoke J. Are Gulf veterans suffering from warrelated illnesses? Federal and civilian hospitalizations examined, June 1991 to December 1994. Am J Epidemiol 2000;151:63-7.

4 Macfarlane G, Thomas E, Cherry N. Mortality among UK Gulf war veterans. Lancet 2000;356:17-21.

5 Doebbeling B, Clarke W, Watson D, Torner J, Woolson R, Voelker M, et al. Is there a Persian Gulf war syndrome? Evidence from a large population- based survey of veterans and nondeployed controls. Am J Med 2000;108:695-704

6 Joseph S and the Comprehensive Clinical Evaluation Program Evaluation Team. Comprehensive clinical evaluation of 20000 Persian Gulf war veterans. Mil Med 1997;162:149-55.

7 Unwin C, Blatchley N, Coker W, Ferry S, Hotopf M, Hull L, et al. Health of UK servicemen who served in the Persian Gulf war. Lance 1999;353:169-78

8 Gray G, Kaiser K, Hawksworth A, Hall F, Barrett-Connor E. Increased postwar symptoms and psychological morbidity among US Navy Gulf war veterans. Am J Trop Med Hyg 1999;60:758-66.

9 Kroenke K, Spitzer R, Williams J. Physical symptoms in primary care: predictors of psychiatric disorders and functional impairment. Arch Fam Med 1994;3:774-9.

10 Fukuda K, Nisenbaum R, Stewart G, Thompson WW, Robin L, Washko RM, et al. Chronic multi-symptom illness affecting air force veterans of the Gulf war. JAMA 1998;280:981-8.

11 Wolfe J, Proctor S, Erickson D, Heeren T, Friedman M, Huang M, et al. Relationship of psychiatric status to Gulf war veterans health problems. Psychosom Med 1999;61:532-40.

12 Ware JJ, Sherbourne C. The MOS 36-item short-form survey (SF-36) conceptual framework and item selection. Med Care 1992;30:473-83.

13 Pickles A, Dunn G. Screening for stratification in two-phase ('two-stage') epidemiological surveys. Statist Meth Med Res 1995;4:73-89.

14 Goldberg D, Williams P. A user's guide to the general health questionnaire Windsor: NFER-NELSON, 1988.

(Accepted 21 May 2002

\title{
Doctors' perceptions of drinking alcohol while on call: questionnaire survey
}

Tahir Ahmad, Jimmy Wallace, James Peterman, Norman A Desbiens

At its monthly ethics conference in September 1999, the department of internal medicine considered consumption of alcohol by doctors. The conference discussed the case of a young doctor who saw a senior colleague drinking heavily at a party and overheard him prescribing a questionably large dose of medication over the telephone. ${ }^{1}$ We discussed whether doctors should drink any amount of alcohol while on call.

Previous studies have considered alcohol use that impairs doctors' judgment and whether doctors should attend an emergency if they have been drinking but are not on call. ${ }^{23}$ Few studies have considered doctors' drinking while on call. We decided to survey doctors to test our hypothesis that doctors rarely drink alcohol while on call but that opinion would differ about usage, depending on doctors' specialty and age.

\section{Participants, methods, and results}

We developed a survey with 10 questions to probe doctors' perceptions about their own and their colleagues' use of alcohol. We obtained a list of all the doctors in Hamilton County, United States, from the American Medical Association in December 1999, took a $20 \%$ random sample from each listed specialty, and mailed up to three rounds of surveys over a six month period beginning in March 2000.

We analysed data using S-PLUS 2000: responses were tallied and binomial 95\% confidence intervals calculated using the binconf function in Frank Harrell's Hmisc library. Logistic regression was used to study the association between individual responses and doctors' years in practice, specialty, and sex. For this hypothesis generating study, two sided $\mathrm{P}$ values of less than 0.05 were considered significant.

Of 206 surveys sent, 135 (65\%) responses were returned. Compared with those who responded, those who did not were more often women $(25 \%(18 / 71) v$ $16 \%(22 / 135))$; had graduated from medical school several years earlier (18 years $v 20$ years); were more often doctors of internal medicine $(31 \%(22 / 71) v$ $17 \%(23 / 135))$; and were less often surgeons and paediatricians $(24 \%(17 / 71)$ v 36\% (49/135)). The mean age of respondents was 48 years, and $88 \%(119 / 135)$ were white.
Doctors' perceptions of using alcohol while on call. Responses to questionnaire (\%; 95\% confidence interval)

\begin{tabular}{|c|c|c|}
\hline Statement & Agree & Disagree \\
\hline Social drinking is acceptable while on call & $19 / 134(14 ; 9$ to 21$)$ & $115 / 134$ (86; 79 to 91$)$ \\
\hline I have encountered doctors whom I suspect have used alcohol while on call & $86 / 135(64 ; 56$ to 72$)$ & $47 / 134$ (36; 28 to 44$)$ \\
\hline I have encountered doctors whom I suspect were impaired by alcohol when they were on call & $36 / 135(27 ; 21$ to 36$)$ & $99 / 135$ (73; 65 to 79$)$ \\
\hline Doctors should not have even a single drink while on call & $99 / 135(73 ; 65$ to 80$)$ & $36 / 135(27 ; 20$ to 35$)$ \\
\hline Patients do not care if I drink alcohol while on call & $3 / 135(2 ; 1$ to 6$)$ & $132 / 135$ (98; 94 to 99$)$ \\
\hline When using alcohol on call, I report that I have done so to any patient I advise or treat & $15 / 129(12 ; 7$ to 18$)$ & $114 / 129(88 ; 82$ to 93$)$ \\
\hline $\begin{array}{l}\text { Doctors have an obligation to inform patients that they have consumed an alcoholic beverage } \\
\text { before advising or treating them }\end{array}$ & $69 / 131(53 ; 45$ to 62$)$ & $62 / 131$ (47; 38 to 55$)$ \\
\hline Alcohol use while on call is a private matter & $35 / 134$ (26; 19 to 34$)$ & $99 / 134(74 ; 66$ to 81$)$ \\
\hline I have consumed alcohol while on call & $32 / 135(24 ; 17$ to 32$)$ & $103 / 135$ (76; 69 to 83$)$ \\
\hline
\end{tabular}

Chattanooga Unit, Department of Medicine, University of Tennessee College of Medicine, 975 East Third Street, Box 94, Chattanooga, TN 37403, USA

Tahir Ahmad internal medicin resident

Norman A

Desbiens professor

University of North Carolina School of Public Health,

Chapel Hill, NC 27599, USA Jimmy Wallace student

Department of Philosophy, University of the South, Sewanee, TN 37383, USA James Peterman professor

Correspondence to: N A Desbiens desbiena@ erlanger.org

BMJ 2002;325:579-80 
Most doctors were against drinking any alcohol while on call (table), but 14\% felt that social drinking was acceptable, and one fourth thought that in their specialty some alcohol use is safe. In response to asking how many drinks a doctor in their specialty could safely drink while on call, 94/129 (73\%) answered 0, 12/129 (9\%) answered 1, 5/129 (4\%) answered 2, 6/129 (5\%) answered 3, and 13/129 (10\%) answered 4 or more. A quarter admitted to drinking alcohol while on call, and $64 \%$ and $27 \%$ reported having encountered colleagues whom they suspected had used or were impaired by alcohol while on call, respectively. Almost all doctors believed that patients care whether they use alcohol while on call, but doctors were divided about their obligation to inform patients before seeing them.

Multivariable analysis showed that sex and specialty were not associated with doctors' responses. Older doctors, however, were more likely to report encountering doctors whom they suspected had used or were impaired by alcohol while on call.

\section{Comment}

Although almost all doctors think that patients care whether they use alcohol while on call, there is substantial disagreement about the use of alcohol while on call and doctors' obligation to inform their patients if they have been drinking. More data need to be obtained about these issues, and the medical profession and society need to discuss the balance between personal freedom and professional obligation to patients. Medical societies need to include stronger declarations about drinking alcohol while on call in their ethical codes, before the issue is decided for them. ${ }^{4}$

Contributors: JW helped conceptualise the study, design the questionnaire, and write the paper. TA supervised the implementation of the study and helped write the paper. JP helped design the questionnaire, review the literature, interpret the findings, and write the paper. ND was involved in all aspects of the study and is guarantor.

Funding: The Internal Medicine Education Foundation paid the costs of the doctor list and postage.

Competing interests: None declared.

1 Ethics case study: the dilemma of dealing with an impaired colleague. In: American College of Physicians ethics manual, 3rd ed. Philadelphia: American College of Physicians, 1993.
2 McAuliffe WE, Rohman M, Breer P, Wyshak G, Santangelo S, Magnuson E. Alcohol use and abuse in random samples of physicians and medical students. Am J Public Health 1991;81:177-82.

3 Stewart JAD. Doctors who do not feel sober enough to drive should avoid helping in medical emergencies. BMJ 1998;317:1158.

4 Opinion on practice matters: substance abuse. In: LeBlang TR, Houdek FG, Basant WE, Poole C, annotators. Code of medical ethics: current opinions with annotations. 1998-9 ed. Chicago: American Medical Association, with annotations.

5 Federal Aviation Administration Regulations 91.17. http://wwwaccess. gpo.gov/ecfr/ (accessed 23 Jul 2002).

(Accepted 9 April 2002)

\section{Corrections and clarifications}

Randomised trial of endoscopy with testing for Helicobacter pylori compared with non-invasive H pylori testing alone in the management of dyspepsia

Our editing process unfortunately introduced an error into a table that appeared in the full (bmj.com) version of this paper by K E L McColl and colleagues (27 April, pp 999-1002). The headings "Positive for $H$ pylori" and "Negative for $H$ pylori" in table 6 were inadvertently interchanged.

Randomised study of long term outcome after epidural versus non-epidural analgesia during labour A temporary problem with a website and a failure in communication led to a website and an acknowledgment not being cited in this paper by Charlotte J Howell and colleagues (17 August, pp 357-9). One of the authors, Richard B Johanson, died before publication of the paper. His Childbirth Without Fear research programme continues (www.childbirthwithoutfear.org.uk).

Sex matters: secular and geographical trends in sex differences in coronary heart disease mortality The authors of this paper, D A Lawlor and colleagues, have told us that the male:female mortality ratios for lung cancer given in the table are wrong for some countries $(B M J$ 2001;323:541-5). The values should read: Hong Kong 2.3, Israel 3.1, Romania 6.1, Kyrgyzstan 6.2, Lithuania 11.5, Slovak Republic 8.6, Japan 3.8, Kazakhstan 7.3, Estonia 9.4, Hungary 4.2, Slovenia 6.7, Germany 5.0, New Zealand 2.2, Northern Ireland 2.5, Portugal 6.4, Republic of Korea 4.2, Russian Federation 10.0, Scotland 2.2, England and Wales 2.4, Ireland 2.5, Italy 6.9, Finland 7.2, Latvia 10.1, Sweden 1.9, Macedonia 6.2, Greece 7.0, Netherlands 4.7, Spain 12.9, Norway 2.6, France 7.7 , Poland 6.4

\section{Submitting articles to the BMJ}

We are now inviting all authors who want to submit a paper to the $B M J$ to do so via the web (http://submit.bmj.com).

Benchpress is a website where authors deposit their manuscripts and editors go to read them and record their decisions. Reviewers' details are also held on the system, and when asked to review a paper reviewers will be invited to access the site to see the relevant paper. The system is secure, protected by passwords, so that authors see only their own papers and reviewers see only those they are meant to. The system is run by Highwire Press, who host bmj.com, and is already being used by 30 journals, including most of the BMJ Publishing Group's specialist journals.

For authors in particular the system offers several benefits. The system provides all our guidance and forms and allows authors to suggest reviewers for their paper-something we'd like to encourage. Authors get an immediate acknowledgement that their submission has been received, and they can watch the progress of their manuscript. The record of their submission, including editors' and reviewers' reports, remains on the system for future reference.

Anyone with an internet connection and a web browser can use the system.

The system itself offers extensive help, and the BMJ's editorial office is geared up to help authors and reviewers if they get stuck. We see Benchpress as part of our endeavour to improve our service to authors and reviewers and, as always, we'd welcome feedback.

Benchpress is accessed via http://submit.bmj.com or via a link from bmj.com 